\title{
Health at the Heart of Urban and Territorial Planning: the WHO's Multi-sectoral Leadership for Human and Planetary Health
}

\author{
Thiago Herick de Sa $(\mathbb{D} \cdot$ Ramona Ludolph • Michael \\ Hinsch • Nathalie Roebbel
}

Accepted: 12 February 2021 / Published online: 24 May 2021

(C) World Health Organization 2021

\section{Commentary}

Health at the Heart of Urban and Territorial Planning

The health and well-being of its residents is perhaps a city's most important asset. The remarkable growth of cities in recent decades has made this understanding ever more evident. The increasing urbanization alongside other global trends like ageing populations and climate change present significant challenges and opportunities to protect people and the planet from health and environmental risks.

Cities offer various services supporting health and well-being, from income and learning opportunities to community life and exchange, fostering creativity and prosperity, not to mention services from urban ecosystem, such as the cooling effects provided by green and blue areas, whenever urban ecosystems are preserved and protected. At the same time, cities also suffer from many unprecedented global environmental changes, such as biodiversity loss, freshwater depletion, soil degradation, and environmental loading with persistent toxic substances [1], which expose residents to a range of health and environmental risks that have the potential to cause a significant burden of infectious and noncommunicable diseases. Examples include air pollution,

Thiago Herick de Sa and Ramona Ludolph shared first authorship.

T. H. de Sa $(\bowtie) \cdot$ R. Ludolph $\cdot$ M. Hinsch $\cdot$ N. Roebbel Department of Environment, Climate Change and Health, World Health Organization, Geneva, Switzerland

e-mail: herickdesat@who.int

noise, water, and soil contamination and urban heat islands. A dearth of space for walking, cycling, and active living further contributes to cities becoming less livable environments for people and epicenters of preventable diseases. Extreme events (e.g., floods, droughts, wildfires, and heat waves), conflict and population displacement, and alterations in the pattern of vector-borne diseases are further examples of the broader relation between global environmental changes and health and well-being.

At the same time, cities can also offer a decisive contribution to address climate change and promote planetary health considering that more than half the world's population is now living in cities, a proportion expected to increase to almost $70 \%$ by 2050 [2]. Despite occupying merely $2 \%$ of the world's landmass, cities are also responsible for approximately $75 \%$ of energyrelated greenhouse gas emissions [3] and largest contributors to national economic wealth. Given the interdependence between cities and the territories they are in, actions taken in cities can have important regional and national repercussions - and even many times beyond, if we consider the global interconnected economy of goods, services, and energy which are part of a city's functioning.

Nowadays, cities face a growing challenge to provide healthy, equitable, and sustainable living conditions for their residents. Moreover, the large variability among the world's cities (e.g., in size, demographics, geographic and historical contexts, resources, and political structure, to name a few) will heavily influence both exposure to stresses, shocks, and hazards as well as cities' 
capacity to respond to and influence public health, safety, and well-being of their citizens. Nevertheless, health is rarely central to decisions affecting these trends, resulting in missed opportunities for health protection and promotion. This challenge can only be mastered through applying an integrated and multi-sectoral health approach, ensuring that human and environmental health go hand in hand. Interventions originating from sectors such as housing, transport, land use, and waste can yield large, immediate public health benefits when they are designed with a health focus in mind. They can also reduce the upward trajectory of greenhouse gas emissions, since many of the pathways to reduce $\mathrm{CO} 2$ emissions are closely linked to sectoral policies towards sustainable mobility, healthy housing, adequate solid waste management, and better land use planning. In addition, cities commonly offer a governance structure that can enable and potentialize integrated and multisectoral action. This includes, for example, making use of the opportunity presented by having a single authority under a city mayor who is empowered to take crosssectoral decisions, for example, on urban planning, procurement of goods and services, and supply of energy [4].

WHO's Multi-sectoral Leadership for Human and Planetary Health

The World Health Organization (WHO) acknowledges the importance of healthy urban environments for population and planetary health. Hence, the WHO is scaling up its work to support countries and cities with the normative guidance, tools, governance, and capacitybuilding mechanisms needed to develop and deliver healthy multi-sectoral solutions for all urban residents. In line with its $13^{\text {th }}$ General Programme of Work, the WHO focuses its actions around the three key areas of (i) strengthening the knowledge base, (ii) providing technical and coordination support to countries, and (iii) providing leadership. Some of the WHO's key actions to deliver on healthier urban environments are outlined below.

\section{Strengthening the Knowledge Base}

In order to strengthen the global knowledge base on urban interventions targeting built and natural environments, integrated urban and territorial planning, and multi-sectoral collaborations, the WHO is stimulating, synthesizing, and applying the best available evidence to design effective policy interventions promoting the health of urban residents.

Housing and Health With about three billion people requiring access to adequate housing by 2030, [5] housing solutions are essential for sustainable development. Meeting the request of several Member States, the WHO has developed the WHO Housing and health guidelines [6] providing normative recommendations on how to reduce health risks from poor housing conditions. The WHO's first guidelines focusing on a sector as opposed to a single risk factor or treatment bring together the best available evidence to make global, normative recommendations on how to address inadequate living space (crowding), low and high indoor temperatures, injury hazards in the home, and accessibility of housing for people with functional impairments. In addition, the guidelines summarize good practices and recommendations on water quality, air quality, neighborhood noise, asbestos, lead, tobacco smoke, and radon, making them a one-stop shop for all of WHO's guidance relevant to housing.

Health in Urban and Territorial Planning One of the main challenges today is to ensure that urban and regional leaders have the knowledge and guidance to integrate health and well-being into their planning processes. Jointly with the UN-Habitat, the WHO has developed in 2020 the guidance document integrating health in urban and territorial planning [7], a sourcebook designed as a tool to assist national governments, local authorities, planning professionals, health professionals, and civil society organizations on how to improve planning frameworks and practice through the incorporation of health considerations, at all levels of governance and across the spatial-planning continuum. The sourcebook explains why health needs to be a part of urban and territorial planning and how to make it happen, offering a comprehensive variety of resources, including frameworks, entry points, guidance, and tools, as well as specific case studies illustrating recommended approaches to bring together planning and public health.

WHO's Urban Health Research Agenda While there has been an increase in research on urban health, from descriptive analysis to effective interventions, many gaps still exist. These relate, for example, to areas such as built environment and urban planning; settings like 
public spaces, slums, and informal settlements; vulnerable populations like the urban poor, children, adolescents, and older populations; and multi-sectoral interventions implemented at a large scale in, e.g., housing, transport, and energy. The WHO plays a crucial role in identifying research gaps and providing leadership to ensure that methodologically and ethically sound research is being conducted to strengthen the evidence base of urban health. The insights gained from such research will be instrumental in developing and implementing multi-sectoral interventions aimed at improving the health of urban residents. Accordingly, the WHO has declared the development of global research priorities for addressing gaps in built and natural environments, urban and territorial planning, and other urban health-related areas as a WHO global public health good. The priorities will be developed through an extensive literature and stakeholder review and an iterative expert consultation process, which are expected to be completed by the end of 2021 .

\section{Technical and Coordination Support to Countries}

The WHO also provides direct support at national and subnational level to countries to promote healthier urban environments. For instance, the Urban Health Initiative model process [8] is a step-wise approach for urban leaders to create demand for action for healthier and more climate-friendly cities by making the best use of local data, knowledge, competencies, and processes to include health in the development equation. The model process comprises six levels of urban transformation, i.e., (i) mapping the current situation, policies, and decision-making processes; (ii) adapting and applying health and economic tools in the local context; (iii) developing and testing local and context-specific scenarios; (iv) building capacity to engage effectively; (v) communication and outreach to sustain and mobilize support; and (vi) monitoring results and refining policy. The pilot phase of the UHI focuses on the reduction of air pollution in Accra and Kathmandu and is currently being completed.

The implementation of the WHO Housing and health guidelines at national, regional, and local levels focuses on producing practical tools to translate the recommendations into policy and practice. It includes, for example, a repository and review of policies promoting healthy housing and a database of case studies highlighting cost benefits and health outcomes of multifactorial interventions. In addition, a method to assess the burden of disease from poor housing conditions to facilitate priority setting and monitoring and evaluation of interventions is currently under development. Communications and capacity-building materials targeted at stakeholders with diverse backgrounds further complement the implementation toolkit.

\section{WHO's Leadership Role}

Finally, the WHO strives to provide leadership to effectively address the world's urban health challenges. The WHO's Global Strategy on Health, Environment and Climate Change [4] aims at transforming the way we tackle environmental risks to health by ensuring a Health in All Policies approach and promoting primary disease prevention and health promotion. This includes strategic urban planning and the full integration of health into the decision-making process of key economic sectors to maximize societal welfare, fulfilling the vision of a world in which sustainable development has eliminated the almost one quarter of the disease burden caused by unhealthy environments. Furthermore, the COVID-19 pandemic has brought to the fore a renewed focus on the importance of urban environments to protect and promote health and has also served as a reminder of the intimate and delicate relationship between people and planet. As part of the pandemic response, the WHO has developed guidance supporting local authorities, leaders, and policy-makers in urban settings in identifying effective approaches and implementing actions to enhance the prevention, preparedness, and response to COVID-19 [9].

\section{Concluding Remarks}

In view of the ongoing pandemic and global trends like urbanization and climate change, cities are facing a unique challenge in providing healthy and sustainable environments for all. Through a concerted effort focusing on strengthening the knowledge base, supporting countries at national and subnational levels, and providing leadership, WHO strives to provide effective solutions to promote healthier and climate-friendly urban environments for all. That understanding is also reflected in WHO's recent manifesto for a healthy recovery from COVID-19 [10], a crisis that served as a reminder for some and a wake-up call for many of the 
inseparable connections between our urban environments, the health of the people, and the health of the planet.

As the Manifesto states, "decisions made in the coming months can either 'lock in' economic development patterns that will do permanent and escalating damage to the ecological systems that sustain all human health and livelihoods, or, if wisely taken, can promote a healthier, fairer, and greener world."

The time to act is now, and WHO stands ready to support countries and cities in this transition, in close collaboration with partners from local and national authorities, other UN agencies, academia, civil society organizations, and the private sector, ensuring direct impact on human and planetary health through our mandate.

Disclaimer The authors are staff members of the World Health Organization. The authors alone are responsible for the views expressed in this article, and they do not necessarily represent the decisions, policy, or views of the World Health Organization.

\section{References}

1. Frumkin H, Haines A. Global environmental change and noncommunicable disease risks. Annu Rev Public Health. 2019;40(1):261-82.

2. United Nations, Department of Economic and Social Affairs, Population Division. 2015. World urbanization prospects: the 2014 revision, (ST/ESA/SER.A/366). https://population.un.org/wup/publications/files/wup2014report.pdf. Accessed 4 May 2021.
3. United Nations Human Settlements Programme. Cities and climate change: global report on human settlements. Narobi: Routledge; 2011.

4. World Health Organization. 2020. WHO global strategy on health, environment and climate change: the transformation needed to improve lives and wellbeing sustainably through healthy environments. World Health Organization. Available at: https://apps.who.int/iris/handle/10665 /331959. Accessed 4 May 2021.

5. Housing: The challenge [website]. Nairobi: UN-Habitat (https://unhabitat.org/topic/housing. Accessed 10 March 2021).

6. World Health Organization. 2018. WHO housing and health guidelines. World Health Organization. Available at: https://apps.who.int/iris/handle/10665/276001. Accessed 4 May 2021.

7. UN-HABITAT \& World Health Organization. 2020. Integrating health in urban and territorial planning: a sourcebook. World Health Organization. Available at: https://apps. who.int/iris/handle/10665/331678. Accessed 4 May 2021.

8. World Health Organization. 2020. Implementing the urban health initiative. https://www.who.int/activities/implementingthe-urban-health-initiative. Accessed 4 May 2021.

9. World Health Organization. 2020. Strengthening preparedness for COVID-19 in cities and urban settings: interim guidance for local authorities. World Health Organization. Available at: https://apps.who.int/iris/handle/10665/331896. Accessed 4 May 2021.

10. World Health Organization. 2020. WHO Manifesto for a healthy recovery from COVID-19. Accessed Oct 13, 2020. https://www.who.int/news-room/feature-stories/detail/whomanifesto-for-a-healthy-recovery-from-covid-19. Accessed 4 May 2021.

Publisher's Note Springer Nature remains neutral with regard to jurisdictional claims in published maps and institutional affiliations. 